\title{
Impact and corrosion resistances of duplex epoxy/enamel coated plates
}

\author{
Fujian Tang, Yi Bao, Yizheng Chen, Yan Tang, Genda Chen ${ }^{1}$
}

Department of Civil, Architectural, and Environmental Engineering, Missouri University of Science and Technology, Rolla, MO 65409-0030, USA

\section{Abstract}

The microstructure, impact resistance, pull-off adhesion strength, and corrosion resistances of duplex epoxy/enamel coating applied on steel plates are investigated experimentally. In comparison with those of individual epoxy and enamel coatings, the duplex coating has lower adhesion strength, higher impact resistance, higher short-term and long-term corrosion resistances both in 3.5 wt.\% $\mathrm{NaCl}$ solution and saturated $\mathrm{Ca}(\mathrm{OH})_{2}$ solution with various chloride concentrations. This is because the outer epoxy fills the micro pores in the inner enamel. Impact induced damage significantly reduces the corrosion resistances of epoxy and duplex coatings but has little effect on the corrosion resistance of enamel coating.

Keywords: Corrosion resistance; Impact resistance; Enamel coating; Epoxy; Duplex coating; EIS; SEM

\section{Introduction}

Reinforced concrete (RC) structures in highway bridges, buildings, dams, and tunnels often undergo physical and chemical deterioration when exposed to aggressive environments. Corrosion of steel reinforcement is one of the most important causes of $\mathrm{RC}$ structural deterioration. It is usually caused by either carbonation of concrete cover or penetration of chloride [1,2]. Carbonation of concrete cover changes the concrete environment from alkaline $(\mathrm{pH}=13)$ to a neutral level or an unfavorable condition for the formation of passive film on the surface of steel reinforcement. Penetration of chloride breaks down the passive film and then initiates steel corrosion in the presence of moisture and oxygen. Once

\footnotetext{
${ }^{1}$ Correspondence to: Genda Chen, Ph.D., P.E., F.ASCE, F.SEI, Professor and Robert W. Abbett Distinguished Chair in Civil Engineering, Department of Civil, Architectural, and Environmental Engineering, Missouri University of Science and Technology, 328 Butler-Carlton Hall, 1401 N. Pine Street, Rolla, MO 65409-0030
} 
initiated, corrosion can cause concrete cover cracking [3,4] and steel section reduction [5], resulting in degraded bond behavior between the steel reinforcement and its surrounding concrete [6] and reduced capacity of structural members [7, 8]. In 2002, the annual direct corrosion cost for replacement and maintenance of U.S. highway bridges was approximately $\$ 13.6 \mathrm{~B}$, and the indirect cost of corrosion due to traffic delay and lost productivity was estimated to be as high as 10 times that of direct corrosion costs [9].

Prevention of steel reinforcement corrosion in RC structures can be achieved either by modifying the properties of concrete cover or using corrosion resistant bars. For example, the properties of concrete can be modified by applying inhibitors $[10,11]$, reducing water-cement ratio, adding high performance admixtures [12-14], and optimizing aggregate gradation. Corrosion resistant bars include non-metallic bars such as fiber reinforced polymer (FRP) bars $[15,16]$, stainless steel bars, stainless steel or copper clad steel bars [17], and coated steel bars [18, 19]. Coating is one of the most effective methods to protect steel bars from corrosion by establishing a chemical and physical barrier between the steel and its corrosive environment. Two of the most widely used coatings are fusion bonded epoxy (FBE) and zinc (galvanized). One of the major problems for epoxy coated bars is the debonding caused by penetration of potassium, sodium ions, and water (humidity), resulting in under-film corrosion due to weak bond with substrate steel $[20,21]$. When the $\mathrm{pH}$ value of concrete pore solution is higher than 13.2 , zinc dissolve accompanied by release of hydrogen gas $[22,23]$. The generation of hydrogen gas increases the porosity of surrounding concrete, resulting in a reduction of steel-concrete bond strength.

Porcelain enamel, as an inorganic coating material, not only provides an aesthetic exterior of industry products but also provides excellent engineering properties, such as abrasion, corrosion, and heat resistances [24]. It is widely used in chemical reactors, heat exchangers, or food-processing vessels due to their excellent chemical stability and workability in harsh environments [25]. The corrosion performance of enamel coating applied on reinforcement steel bars has been investigated in our previous studies [26, 27]. The effects of bar deformation, external damage, coating thickness, and corrosive environments on the corrosion resistance of enamel steel bars were thoroughly studied. Enamel coating is chemically 
47 reacted with both concrete and steel and thus provides a smooth transition zone at the concrete-steel

48 interface. Enamel coating can prevent the so-called under-film corrosion that has been associated with the

49 fusion bonded epoxy (FBE) coating. However, while it can increase bond strength between steel bars and

50 concrete, enamel coating mixed with calcium silicate has lower corrosion resistance than that of the

51 enamel coating itself. The mixed enamel is also brittle and susceptible to impact damage during shipping

52 and handling. Even intact enamel coated steel bars are less corrosion resistant than intact FBE coating due

53 to micro pores in enamel coating.

54 In this study, a duplex epoxy/enamel coating is developed and its microstructure, impact resistance,

55 adhesion strength, short-term and long-term corrosion resistances are characterized. It consists of an outer

56 layer of epoxy and an inner layer of enamel. The outer epoxy was used to increase the impact resistance

57 to external damage and provide an additional barrier to corrosion. The inner enamel was intended to

58 chemically bond with the substrate steel, preventing under-film corrosion. For comparison purposes, both

59 epoxy and enamel coated specimens were also prepared and tested. The microstructures of coatings were

60 examined using scanning electron microscopy (SEM), the impact resistance was investigated by impact

61 test, and the adhesion strengths were determined by pull-off test. The corrosion performance was

62 investigated with electrochemical impedance spectroscopy in $3.5 \mathrm{wt} . \% \mathrm{NaCl}$ solution for 1.5 hours and in

63 simulated concrete pore solutions with various chloride concentrations for 31 days. Effect of impact

64 damage on both the short-term and long-term corrosion resistances was also assessed.

\section{2. Material and methods}

\subsection{Preparation of enamel and epoxy coatings}

67 Enamel is a silicate-based material that can be applied to steel surface using either a wet or dry 68 process. In this study, enamel mixed with calcium silicate is coated on steel specimens in the wet process 69 of enamel slurry application. The enamel slurry was prepared by mixing water, enamel glass frit, cement, 70 clay and borax according to a proportion of 1.00:1.20:1.20:0.17:0.01 by weight. The chemical 
71 composition of the glass frit is given in Table 1. Type I Portland cement was used and its chemical

72 composition was determined and listed in Table 2. The glass frit and cement were added first to water and

73 mixed for $20 \mathrm{~min}$, and then clay and borax as suspension agents were added and mixed again for $3.5 \mathrm{hr}$.

\section{Table 1}

75 Chemical composition of enamel glass frit

\begin{tabular}{ccccccccccccc}
\hline Composition & $\mathrm{SiO}_{2}$ & $\mathrm{~B}_{2} \mathrm{O}_{3}$ & $\mathrm{Na}_{2} \mathrm{O}$ & $\mathrm{K}_{2} \mathrm{O}$ & $\mathrm{CaO}$ & $\mathrm{CaF}_{2}$ & $\mathrm{Al}_{2} \mathrm{O}_{3}$ & $\mathrm{ZrO}_{2}$ & $\mathrm{MnO}_{2}$ & $\mathrm{NiO}$ & $\mathrm{CoO}$ & Total \\
\hline Amount (wt.\%) & 44.0 & 19.3 & 15.8 & 2.8 & 0.0 & 4.7 & 4.6 & 5.3 & 1.5 & 1.0 & 0.9 & 100 \\
\hline
\end{tabular}

76

77

78

79

80

81

82

83

84

Table 2

Chemical composition of Type-I Portland cement

\begin{tabular}{ccccccccccccc}
\hline Loss on ignition & $\mathrm{SiO}_{2}$ & $\mathrm{Al}_{2} \mathrm{O}_{3}$ & $\mathrm{CaO}$ & $\mathrm{MgO}$ & $\mathrm{SO}_{3}$ & $\mathrm{Na}_{2} \mathrm{O}$ & $\mathrm{K}_{2} \mathrm{O}$ & $\mathrm{Cl}$ & $\mathrm{TiO}_{2}$ & $\mathrm{Fe}_{2} \mathrm{O}_{3}$ & $\mathrm{P}_{2} \mathrm{O}_{5}$ & $\mathrm{Total}$ \\
\hline 3.98 & 19.48 & 6.80 & 55.35 & 3.32 & 4.35 & 2.39 & 1.00 & 0.02 & 0.20 & 2.18 & 0.19 & 99.27
\end{tabular}

Carbon steel plates, $76.2 \mathrm{~mm} \times 38.1 \mathrm{~mm} \times 3.18 \mathrm{~mm}$ (length $\times$ width $\times$ depth), were prepared for various tests. The chemical composition by weight is: $0.27 \% \mathrm{C}, 0.28 \% \mathrm{Si}, 1.03 \% \mathrm{Mn}, 0.05 \% \mathrm{~S}, 0.03 \% \mathrm{P}$, and the balance Fe. Enamel was coated on the steel plates by Pro Perma Engineered Coatings (Rolla, MO, USA). Prior to coating, all steel plates were sand-blasted and cleansed with a commercially available cleaning solvent. Each cleaned plate was dipped into the enamel slurry, and heated for 2 min at $150{ }^{\circ} \mathrm{C}$ to drive off moisture, then moved into a gas-fired furnace at $810{ }^{\circ} \mathrm{C}$ for 10 minutes, and finally cooled to room temperature. The heat treatment melted the glass frit and bonded the enamel to the substrate steel. commercially available product 156 Rebar Green Epoxy Coating (Aervoe Industries Incorporated, USA). It is composed of $35 \%$ hydrocarbon propellant, $35 \%$ n-butyl acetate, $29 \%$ acetone, and 1\% aliphatic petroleum distillates by weight. For duplex coating, the enamel coating was applied first to the cleaned steel plates and the epoxy was then sprayed on top of the enameled plates.

To study the impact resistance of coatings and the effect of impact-induced damage on the corrosion resistance, some coated steel plates were pre-damaged using an impact test apparatus designed according to the ASTM Standard G14 [28]. The apparatus consists of a $0.91 \mathrm{~kg}$ steel rod with a circular flat head, a vertical section of hollow aluminum tubing to guide the rod, and a horizontal section of steel angle to 
94 position the coated steel plate. The weight rod was dropped from a height of $45.7 \mathrm{~cm}$ to damage the 95 coating.

96

97

\subsection{Characterization of coatings and pull-off test}

Microstructures of the epoxy, enamel and duplex coatings were examined with scanning electron microscopy (SEM; Hitachi S4700). A small piece of coated steel plate was cut across the cross section and cold-mounted with EpoxyMount. The cross section was then ground with silicon carbide papers to 1200 grit. The ground samples were rinsed with deionized water, cleansed with acetone, and finally dried prior to SEM imaging.

The adhesion strength of coating with its substrate steel plate is determined following ASTM D454109 with an automatic PosiTest pull-off tester [29]. To reduce the risk of adhesive failure, the bottom face of a 14-mm-diameter dolly was slightly abraded with sandpaper, cleansed with acetone, and adhered to the surface of coated steel plate with Araldite multi-purpose adhesive. After the adhesive was cured for 24 $\mathrm{hr}$, scoring around the perimeter of the dolly was employed and the dolly was pulled-off perpendicular to its interface with the coated steel plate at a stress rate of $0.41 \mathrm{MPa} / \mathrm{s}$. The maximum strength of each coated steel plate was recorded.

\subsection{Electrochemical corrosion tests}

Fig. 1 shows the dimensions of each steel plate specimen for electrochemical corrosion tests. For each coated steel plate, one corner was ground off to expose the steel for soldering with a copper wire for electrochemical measurements. All four side edges and the back face of the steel plate were covered with EpoxyMount (ALLIED). Therefore, only the center portion on the front face of all steel plates, approximately $12.5 \mathrm{~cm}^{2}$, was potentially exposed to the test solution. To quantify the variation of test data, three identical specimens were prepared and tested in each condition, including a combination of three coatings (enamel-EN, epoxy-EP, and duplex coating - DUP), two damage levels (undamaged - U and 
damaged - D), and two corrosive environments (3.5 wt.\% $\mathrm{NaCl}$ solution and saturated $\mathrm{Ca}(\mathrm{OH})_{2}$ solution).

118 For comparison purposes, six uncoated steel plates (UN) were also prepared and tested. Therefore, a total 119 of forty two specimens were tested. In the following presentation, UEP stands for undamaged epoxy 120 coating, UEN and DEN represent undamaged and damaged enamel coatings, UDUP-EP and DDUP-EP 121 denote the outer epoxy of undamaged and damaged duplex coatings, and UDUP-EN and DDUP-EN are 122 the inner enamel of undamaged and damaged duplex coatings.

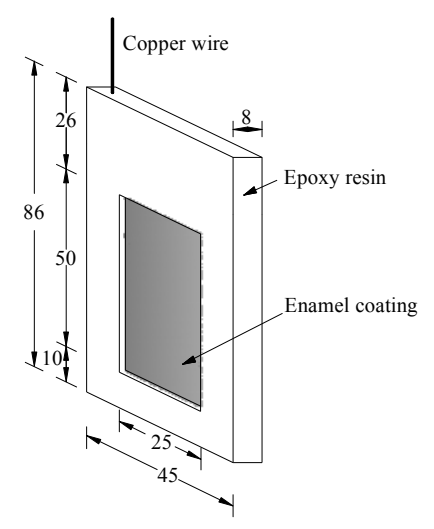

Fig. 1. Schematic view of the steel plate used in electrochemical experiments (unit: $\mathrm{mm}$ ).

Two types of solution used in this study are 3.5 wt.\% sodium chloride $(\mathrm{NaCl}$, Fisher Scientific International Inc.) and saturated calcium hydroxide $\left(\mathrm{Ca}(\mathrm{OH})_{2}\right.$, Fisher Scientific International Inc.). The $\mathrm{NaCl}$ solution was made by dissolving $\mathrm{NaCl}$ powder into distilled water that was used to test the shortterm corrosion resistance of steel plates. Open-circuit potential was recorded immediately after steel plates were immersed in the salt solution for up to 3400 seconds, and then electrochemical impedance spectroscopy (EIS) was performed. The saturated $\mathrm{Ca}(\mathrm{OH})_{2}$ solution was prepared by mixing certified $\mathrm{Ca}(\mathrm{OH})_{2}$ powder into distilled water that was used to simulate the concrete pore solution and investigate the long-term corrosion resistance [30-32]. The $\mathrm{Ca}(\mathrm{OH})_{2}$ powder was added into the distilled water until some residue could be observed at the bottom of the solution, and the $\mathrm{pH}$ value was measured to be 12.5 at room temperature. In order to observe both the passivation and de-passivation processes, $\mathrm{NaCl}$ was added incrementally in saturated $\mathrm{Ca}(\mathrm{OH})_{2}$ solution to reach $0.01,0.05,0.10,0.50,1.00 \mathrm{~mol} / \mathrm{L}$ concentrations. The steel plates were first immersed in the saturated $\mathrm{Ca}(\mathrm{OH})_{2}$ solution free of chloride for 
138 of passive film was observed by measuring the open circuit potential evolution of uncoated steel plates.

139 After three days, open circuit potential and EIS were performed on all steel plates. At the completion of

140 the electrochemical tests, $\mathrm{NaCl}$ powder were added into the solution to achieve a chloride concentration

141 of $0.01 \mathrm{~mol} / \mathrm{L}$, and the steel specimens continued to be immersed for another three days prior to the next

142 electrochemical measurements. This process was repeated until the chloride concentration in the solution

143 reached $1.00 \mathrm{~mol} / \mathrm{L}$. After the chloride concentration reached $1.00 \mathrm{~mol} / \mathrm{L}$, the electrochemical tests

144 continued every three days for a total of 31 days of test. To reduce the potential carbonation of the

145 saturated $\mathrm{Ca}(\mathrm{OH})_{2}$ solution, the glass container remained covered with plastic sheet except $\mathrm{NaCl}$ powder

146 was added.

147 The typical three electrodes setup was used for both the open-circuit potential and EIS tests. That is, a $14825.4 \mathrm{~mm} \times 25.4 \mathrm{~mm} \times 0.254 \mathrm{~mm}$ platinum sheet works as a counter electrode, a saturated calomel electrode 149 (SCE) as a reference electrode, and the steel plate specimen as the working electrode. All three electrodes 150 were connected to a Gamry, Reference 600 potentiostat/galvanostat/ZRA for data acquisition. EIS tests 151 were carried out next at a sampling rate of 5 points per decade with an applied sinusoidal potential of 10 $152 \mathrm{mV}$ amplitude around the open-circuit potential $\left(E_{\text {ocp }}\right)$ and frequency ranging from $100 \mathrm{kHz}$ to $5 \mathrm{mHz}$.

\section{3. Results and discussion}

154 3.1Microstructure of coatings and impact-induced damage

155 Fig. 2 shows the cross-sectional SEM images at steel-coating and epoxy-enamel interfaces of epoxy, 156 enamel, and duplex coated steel plates with different magnifications. The enamel coating is 157 approximately $260 \mu \mathrm{m}$ thick and possesses an amorphous structure with partially connected pores through 158 the entire coating thickness (Fig. 2a-1). The micro pores were formed by release of gases (e.g. $\mathrm{H}_{2}$ and CO) 159 generated during the enameling process [33]:

$\mathrm{Fe}+\mathrm{H}_{2} \mathrm{O} \uparrow=\mathrm{H}_{2} \uparrow+\mathrm{FeO}$ 
162
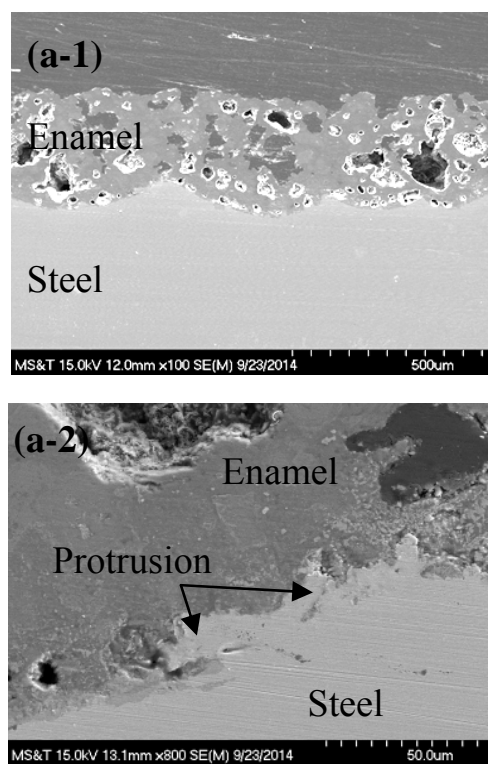
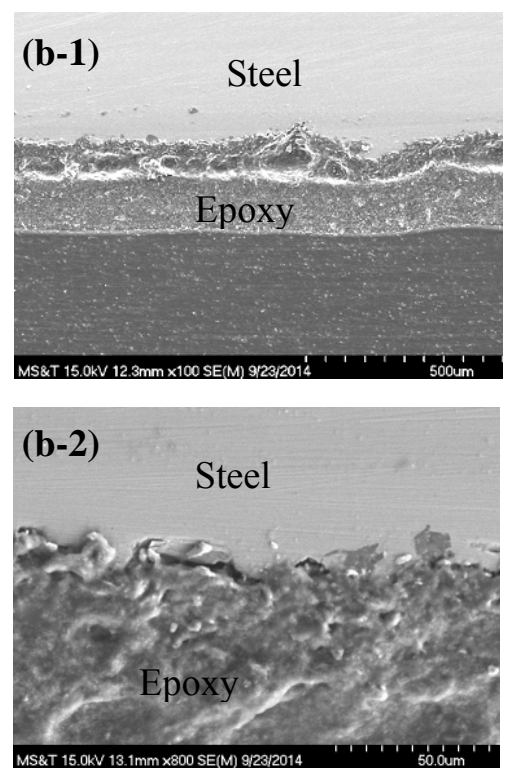
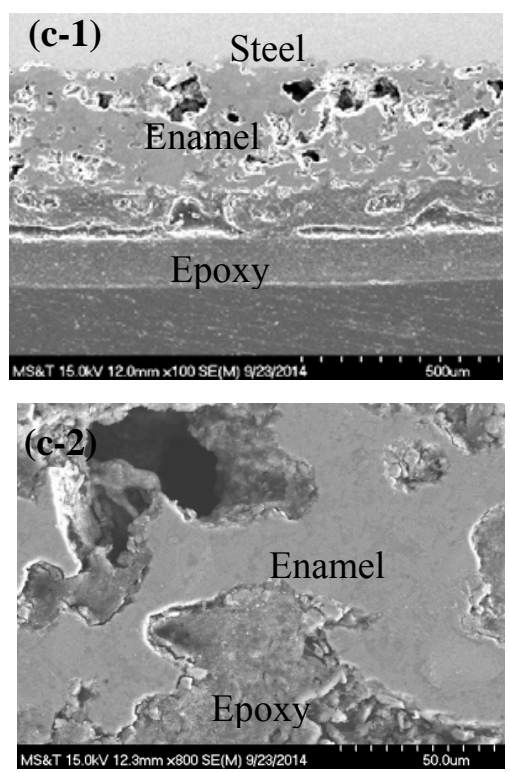

Fig.2. Cross-sectional SEM images of (a) enamel, (b) epoxy, and (c) duplex coated steel plates with different magnifications: (1) 100×, and (2) 800×.

Fig. 2(a-2) shows the magnified enamel-steel interface at which small Fe-rich protrusions are

168 interconnected to form the so-called anchor points. These protrusions increase the roughness and thus

169 adhesion strength of the enamel-steel interface [34]. As shown in Fig. 2(b-1), the epoxy coating is 170 approximately $230 \mu \mathrm{m}$ thick and its interface with steel is mechanically interlocked as shown in Fig. 2(b-

171 2). As indicated in Fig. 2(c-1), the duplex coating has a thickness of $550 \mu \mathrm{m}$ and shows two distinct layers

172 of $300 \mu \mathrm{m}$ thick enamel and $250 \mu \mathrm{m}$ thick epoxy. At the enamel-epoxy interface, epoxy penetrates

173 through the partially connected pores of the enamel layer to approximately $150 \mu \mathrm{m}$ deep, resulting in a

174 high interlocking action as illustrated in Fig. 2(c-2). The coating thicknesses are summarized in Table 3.

175 Table 3 Thickness, failure mode, and adhesion strength of all three coatings.

\begin{tabular}{llll}
\hline Coating type & Epoxy & Enamel & Duplex \\
\hline Thickness $(\mu \mathrm{m})$ & $227 \pm 28$ & $264 \pm 41$ & $558 \pm 12$ \\
Failure mode & Cohesive & Mixed & Mixed \\
adhesion strength $(\mathrm{MPa})$ & $7.74 \pm 0.57$ & $7.31 \pm 0.34$ & $7.20 \pm 1.01$ \\
\hline
\end{tabular}


Fig. 3 shows the damage induced by impact test on the three representative coated specimens. Due to 177 its micro pores, the enamel coating was partially flaked without exposing the enamel-steel interface as 178 displayed in Fig. 3a. The epoxy coating was delaminated from its substrate steel due to their weak bond 179 (Fig. 3b). The duplex coating, even dented, was subjected to significantly less damage than both the 180 enamel and epoxy coatings as shown in Fig. 3c. This is because the stiffness from epoxy through enamel 181 to steel gradually increased. As a result, the inner enamel layer of the duplex coating was protected from 182 impact damage by the outer epoxy layer while the outer epoxy layer was less susceptible to impact 183 damage with relatively soft enamel substrate. The duplex epoxy/enamel coating thus has a higher impact 184 resistance than both epoxy and enamel coatings.
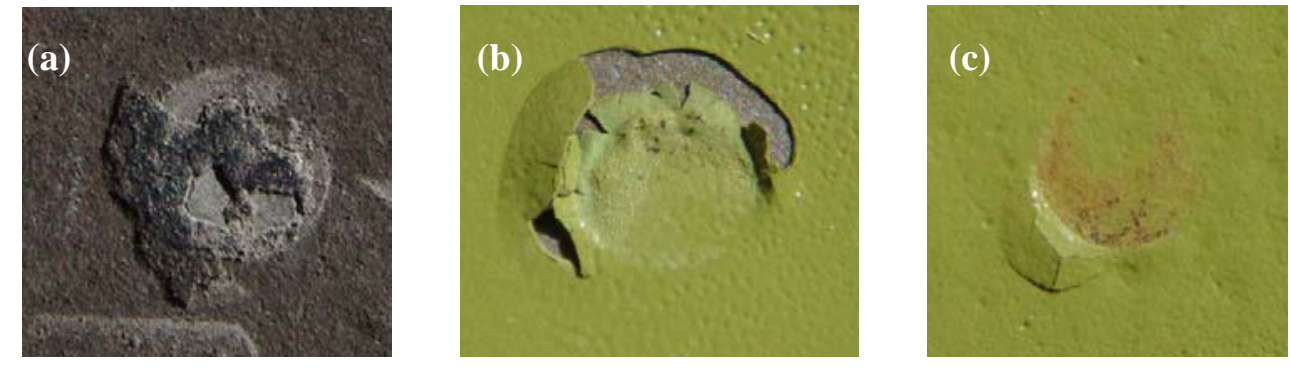

Fig. 3. Impact induced coating damage: (a) enamel, (b) epoxy, and (c) duplex epoxy/enamel.

\subsection{Pull-off adhesion strength}

At the completion of pull-off tests, the dollies were separeated from their steel plate substrates. Optical micrographs of fracture surfaces of representative peeled steel plates are presented in Fig. 4. In a pull-off adhesion test, four possible failure modes may occur. They include (1) adhesion break between the coating and its steel substrate; (2) cohesion break within the coating layer; (3) glue break, and (4) a combination of above breaks at multiple locations or mixed break.

As shown in Fig. 4a, enamel breaks within the coating layer (cohesive break). This is because the enamel coating has a porous structure and the glue penetrates through the partially connected pores, forming an excellent glue-dolly interface. Both the epoxy and duplex coatings have a mixed failure mode 
involving breaks at multiple locations. The epoxy coating mostly fails inside the coating (cohesive break)

197 but sometimes at the dolly-epoxy interface (glue break). There is no failure at the epoxy-steel interface as

198 displayed in Fig. 4b. Duplex coating fails within the outer epoxy and the inner enamel layers as shown in

199 Fig. 4c.

Three pull-off tests were conducted on each type of coated steel plates. As summarized in Table 3, the average and the standard deviation of three adhesion strengths measured were calculated for three types 202 of coatings. The epoxy coating has the highest adheison strength with an average of 7.74 MPa, the duplex 203 coating has the lowest adhesion strength 7.20 MPa, and the enamel coating has an average adhesion 204 strength of 7.31 MPa. This is because the epoxy coating is a dense layer that is mechanically interlocked 205 with substrate steel while the enamel coating or the inner enamel of the duplex coating is a porous layer 206 with micro pores across which fracture happened. The variation of adhesion strengths for every type of coating is small, indicating consistent measurements.
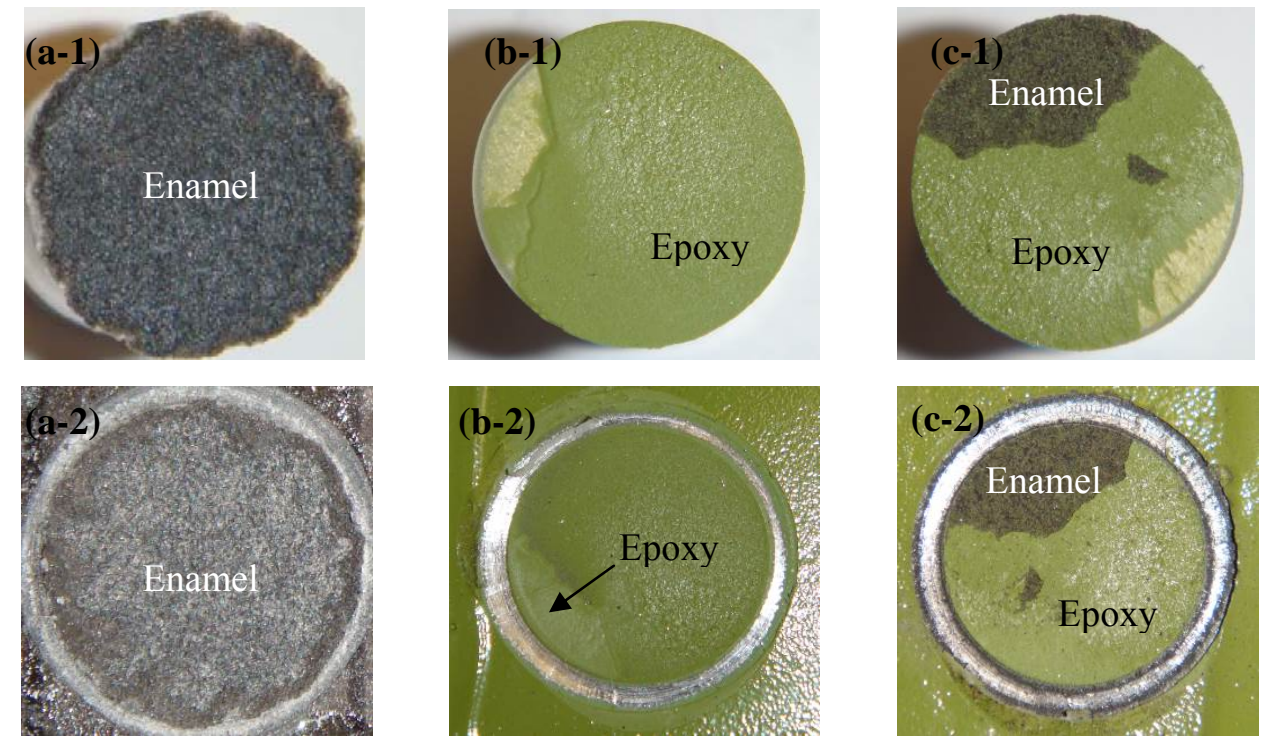

Fig. 4. Fracture surface morphologies of steel plates coated with (a) enamel, (b) epoxy, and (c) duplex epoxy/enamel coatings: (1) dolly, and (2) steel plates. 
Fig. 5 shows the open-circuit potential evolution of uncoated and coated steel plates after they have been immersed in $3.5 \mathrm{wt} . \% \mathrm{NaCl}$ solution for up to 3400 seconds. For uncoated steel plates as indicated

216 in Fig. 5a, the open circuit potentials decreased approximately $70 \mathrm{mV}$ for specimens UN\#1 and UN\#2 and

$21750 \mathrm{mV}$ for specimen UN\#3 in the first 800 seconds. This is attributed to the rapid growth and enlargement

218 of active corrosion sites on the surface of steel plates. After 800 seconds, the potentials become stable

219 around a value of $-720 \mathrm{mV}$ for all three specimens, probably due to the stabilization of corrosion activities 220 over the entire exposed surface of steel plates.

221 Fig. 5b shows the open circuit potential of enamel coated steel plates. They are initially around -250 $222 \mathrm{mV}$ and slowly decrease to a stable value of approximately $-300 \mathrm{mV}$ at 3400 seconds. The open circuit 223 potentials of enamel coated steel plates with impact damage are close to those of enamel coated steel 224 plates without impact damage. This is because enamel coating has a porous structure with open pores, and 225 introduction of the external damage does not significantly change the entire exposed steel areas at open pores. Therefore, the corrosion activities on these enamel coated steel plates are close to each other. 227 Compared with the uncoated steel plates, the enamel coated steel plates have higher open potential potentials since the coating barrier prevented steel from direct contact with salt solution.

229 Steel plates with epoxy and duplex coatings show a similar trend of potentials over time, both decreasing rapidly in the beginning and then approaching stable values as shown in Figs. 5c and 5d. After 2313400 seconds immersion in salt solution, the final open circuit potentials are around $-200 \mathrm{mV}$ for epoxy 232 coated steel plates and $-95 \mathrm{mV}$ for duplex coated steel plates, indicating low activities of corrosion. 233 However, the open-circuit potential of steel plates with impact damage reduced to $-590 \mathrm{mV}$ for epoxy 234 coated steel plates and $-495 \mathrm{mV}$ for duplex coated steel plates after 3400 seconds. This is because impact 235 damage created pathways in the coating layer, allowing electrolyte to penetrate to the substrate steel 236 surface, resulting in active corrosion. The open circuit potentials of epoxy coated steel plates with impact 237 damage are lower than that of duplex coated steel plates with damage. This is because the impact-induced 238 damage area on epoxy coating is larger than that on duplex coating as shown in Fig. 3. 
(a)
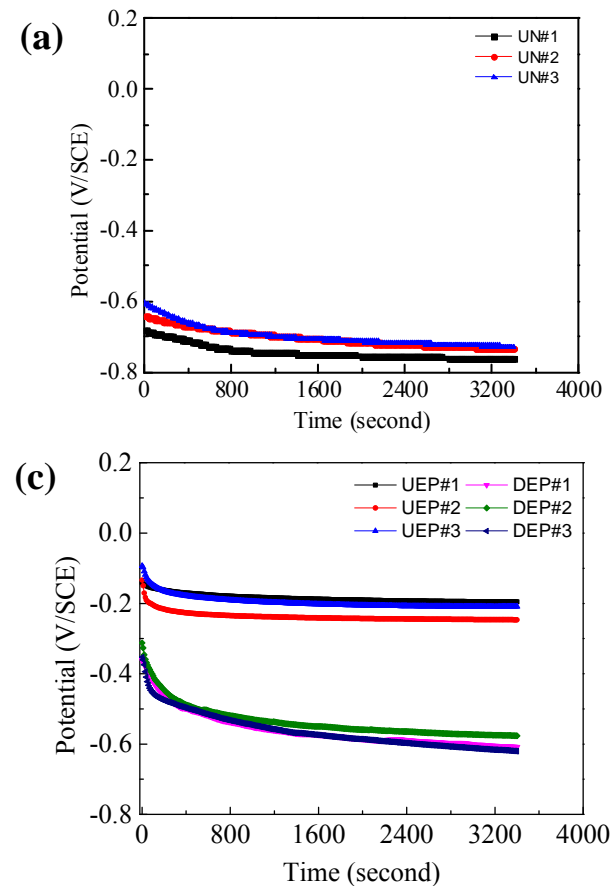
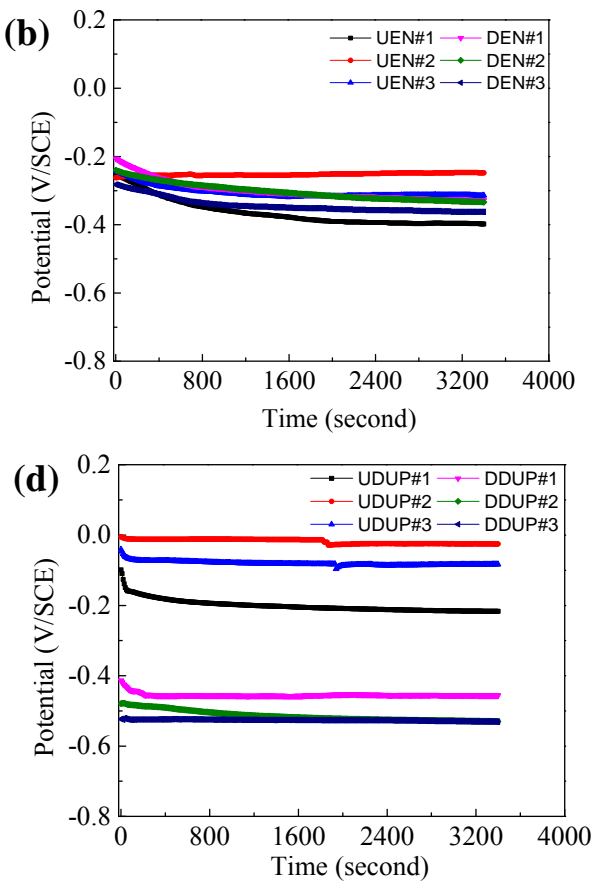

Fig. 5. Open circuit potential evolution over time for (a) uncoated, (b) enamel coated, (c) epoxy coated, and (d) duplex coated steel plates.

Fig. 6 shows the impedance diagrams of three uncoated, three enamel coated, three epoxy coated, and three duplex coated steel plates in 3.5 wt. $\% \mathrm{NaCl}$ solution in the format of Bode plots. Dot point means measurement data (Meas.) and solid line represents the fitting results (Ftd.) using various equivalent electrical circuit (EEC) models as shown in Fig. 7. For the uncoated steel plates as shown in Fig. 6a, one time constant is observed from the phase angle-frequency diagram, which corresponds to the double layer and surface polarization effects $[35,36]$. The impedance spectra of the uncoated steel plates can be simulated by the EEC (I) model in Fig. 7. In this case, $R_{\mathrm{s}}$ is the uncompensated electrolyte resistance, $C P E_{\mathrm{dl}}$ represents the capacitive behavior of the double-layer, and $R_{\mathrm{ct}}$ is the charge transfer resistance. The introduction of $C P E_{\mathrm{dl}}$ is due to irregularities of the exposed steel surface, such as surface roughness, random distribution of corrosion microcells, and certain processes associated with an irregular distribution of the applied potential [37, 38]. Mathematically, the impedance of a CPE with two parameters $Y$ and $n$ can be expressed into [38]:

$$
Z_{C P E}=Y^{-1} \cdot(j \omega)^{-n}
$$


where $Y$ is the CPE-constant with unit $\Omega^{-1} \mathrm{~cm}^{-2} \mathrm{~s}^{\mathrm{n}}$, which is directly proportional to the double layer 257 capacitance of pure capacitive electrode [32], $n$ is the CPE-power $(0<n<1), j$ is the imaginary unit $\left(j^{2}=-1\right)$, 258 and $\omega$ is the angular frequency of the applied alternative current ( $\omega=2 \pi f$, $f$ is the frequency in $\mathrm{Hz})$.

259

260

261
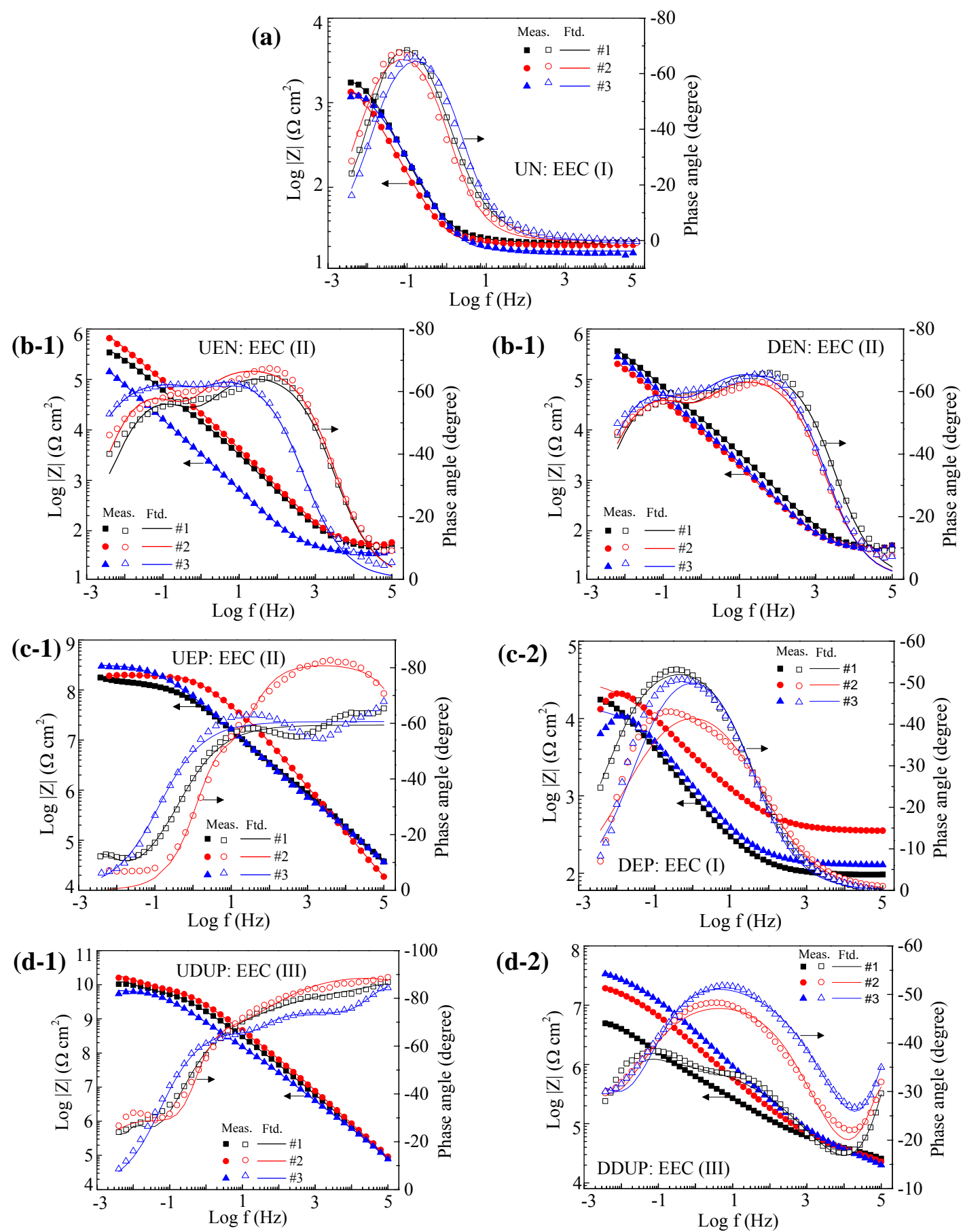

Fig. 6. Bode plots of (a) uncoated (UN), (b) enamel (EN), (c) epoxy (EP), and (d) duplex (DUP) coated steel plates (1) with undamaged (U) and (2) with damaged (D) in $3.5 \mathrm{wt} \% \mathrm{NaCl}$ solution. 



266

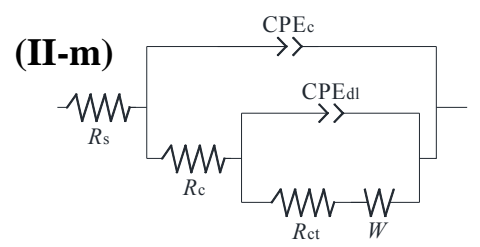

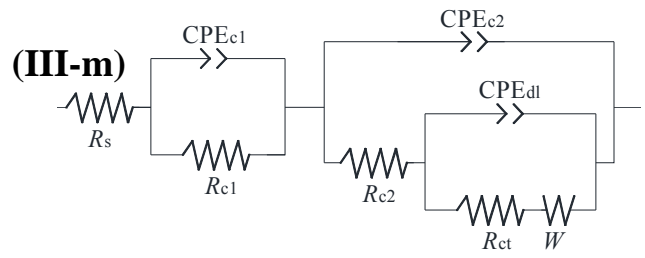

267

268

269

270

271

272

273

274

275

276

277

278

279

280

281

282

283

284

Fig. 7. Equivalent electrical circuit models.

Unlike the uncoated steel plates, the enamel and epoxy coated steel plates have two time constants in the phase angle-frequency diagram as shown in Figs. 6(b-1) and 6(c-1). The first time constant in the high frequency range is associated with the properties of enamel/epoxy coating, and the second time constant in the low frequency range is related to the pitting corrosion at active sites with open pores in enamel coating and pin holes in epoxy coating [39, 40]. The EEC (II) model in Fig. 7 was used to fit each impedance spectrum, in which $R_{\mathrm{c}}$ is the pore resistance of the coating [41], $C P E_{\mathrm{c}}$ represents the nonhomogenous capacitive behavior of coating layer, which is mainly from the random distribution of open pores and pin holes $[42,43]$.

For the duplex coated steel plates as shown in Fig. 6(d-1), the EEC (III) model was used [44]. In this model, $C P E_{\mathrm{c} 1}$ and $R_{\mathrm{c} 1}$ represent the capacitance and pore resistance of the outer epoxy layer, $C P E_{\mathrm{c} 2}$ and $R_{\mathrm{c} 2}$ represent the capacitance and pore resistance of the inner enamel layer, and $C P E_{\mathrm{dl}}$ and $R_{\mathrm{ct}}$ reflects the pitting corrosion behavior.

Impact induced damage does not significantly affect the impedance diagram of enamel coated steel plates as observed from a comparison of Fig. 6(b-1) and Fig. 6(b-2). This is because the microstructure of enamel coating is already porous and little affected by impact damage. However, the impact damage changes the impedance spectra of the epoxy and duplex coated steel plates as shown in Figs. 6(c-2) and 6(d-2), respectively. For the epoxy coated steel plates with impact damage, the time constant related to 
the coating properties disappear due to the significant damaged area as seen in Fig. 3b. Therefore, the EEC (I) model was used, and the electrochemical properties obtained would be related to the pitting corrosion at the exposed steel area induced by impact test. For the duplex coated steel plates with impact damage, the EEC (III) model is still used for comparison with the steel plates without impact damage.

Fig. 8 compares the (average \pm standard deviation) pore resistance and capacitance of epoxy coating, enamel coating, the outer epoxy and the inner enamel of duplex coating. The coating capacitance in Fig. $8 \mathrm{~b}$ is determined from the two parameters $(Y, n)$ of a CPE and its associated parallel resistance $R$ by [45, 292 46]:

in which $R, Y$, and $n$ are respectively referred to $R_{\mathrm{c}} / R_{\mathrm{c} 1} / R_{\mathrm{c} 2}, Y_{\mathrm{c}} / Y_{\mathrm{c} 1} / Y_{\mathrm{c} 2}$, and $n_{\mathrm{c}} / n_{\mathrm{c} 1} / n_{\mathrm{c} 2}$ corresponding to $C P E_{\mathrm{c}} / C P E_{\mathrm{c} 1} / C P E_{\mathrm{c} 2}$ in EEC (I, II, and III) models in Fig. 7.

296 (a)

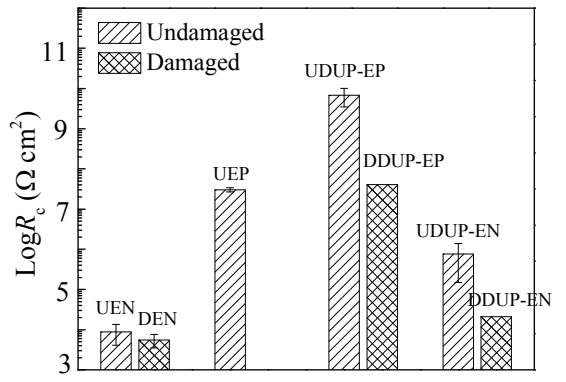

(b)

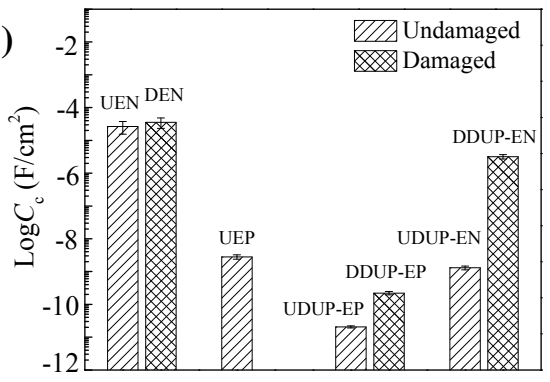

Fig. 8. Comparison of EIS parameters: (a) pore resistance of coating and (b) coating capacitance.

Pore resistance and capacitance of coatings represent a degree of ability of coating to resist the penetration of electrolyte solution, which is closely related to the coating microstructures such as open pores, pin holes, and damage in the coating layer [47, 48]. Enamel coating has the lowest average pore resistance $\left(8.88 \mathrm{k} \Omega \mathrm{cm}^{2}\right)$ and the highest average capacitance $\left(26.4 \mu \mathrm{F} / \mathrm{cm}^{2}\right)$, while the duplex coating has the highest average pore resistance $\left(6.80 \mathrm{G} \Omega \mathrm{cm}^{2}\right)$ and the lowest average capacitance $\left(20.6 \mathrm{pF} / \mathrm{cm}^{2}\right)$. The average pore resistance and capacitance of epoxy coating are $30.3 \mathrm{M} \Omega \mathrm{cm}^{2}$ and $2.81 \mathrm{nF} / \mathrm{cm}^{2}$. The overall volume of open pores in the enamel coating is larger than the volume of pin holes in the epoxy and duplex 
coatings. Therefore, more electrolytes penetrate through the enamel coating than the epoxy and duplex coatings, resulting in increased conductivity and higher coating capacitance. For the epoxy coating with

307 impact damage, the parameters representing the pore resistance and capacitance were not extracted due to

308 the use of a different EEC model as discussed previously. Compared with the enamel coating, the inner 309 enamel of duplex coating displays higher pore resistance and lower capacitance. Similarly, the outer 310 epoxy of the duplex coating also has higher pore resistance and lower capacitance than the epoxy coating.

311 This is because the outer epoxy in the duplex coating penetrates through the porous inner enamel, 312 resulting in a thicker layer than the epoxy coating. On the other hand, the outer epoxy of the duplex 313 coating fills the connected pores in the inner enamel of the duplex coating, resulting in a decreased 314 volume of open pores. Impact damage significantly reduces the pore resistance and increases the capacitance of duplex coating.

Fig. 9 compares the charge transfer resistance $R_{\mathrm{ct}}$ and double layer capacitance $C_{\mathrm{dl}}$ for uncoated, 317 enamel, epoxy and duplex coated steel plates. The double layer capacitance $C_{\mathrm{dl}}$ of the $C P E_{\mathrm{dl}}$ in parallel 318 with $R_{c t}$ was calculated from Equation (3) when $Y=Y_{\mathrm{dl}}, R=R_{\mathrm{ct}}$, and $n=n_{\mathrm{dl}}$. Charge transfer resistance 319 reflects the ease of charge across the interface, which is inversely proportional to corrosion rate [49]. 320 Among all the tested specimens, uncoated steel plates have the lowest $R_{\mathrm{ct}}\left(=1.93 \mathrm{k} \Omega \mathrm{cm}^{2}\right)$ and the highest $321 C_{\mathrm{dl}}\left(=1.08 \mathrm{mF} / \mathrm{cm}^{2}\right)$, which is consistent with the results from other studies [50, 51]. The duplex coated 322 steel plates have the highest $R_{\mathrm{ct}}\left(=18.6 \mathrm{G} \Omega \mathrm{cm}^{2}\right)$ and the lowest $C_{\mathrm{dl}}\left(=1.25 \mathrm{nF} / \mathrm{cm}^{2}\right)$. In comparison with 323 the enamel coated steel plates, the damaged epoxy coated plates have a lower $R_{\mathrm{ct}}$ and a higher $C_{\mathrm{dl}}$ even 324 though the undamaged epoxy coated plates have a higher $R_{\mathrm{ct}}$ and a lower $C_{\mathrm{dl}}$. The reduction in charge 325 transfer resistance due to impact damage is significant in epoxy and duplex coated steel plates but 326 negligible in enamel coated steel plates. Overall, the duplex coating is most corrosion resistant among 327 three coatings investigated regardless of the state of impact damage. 

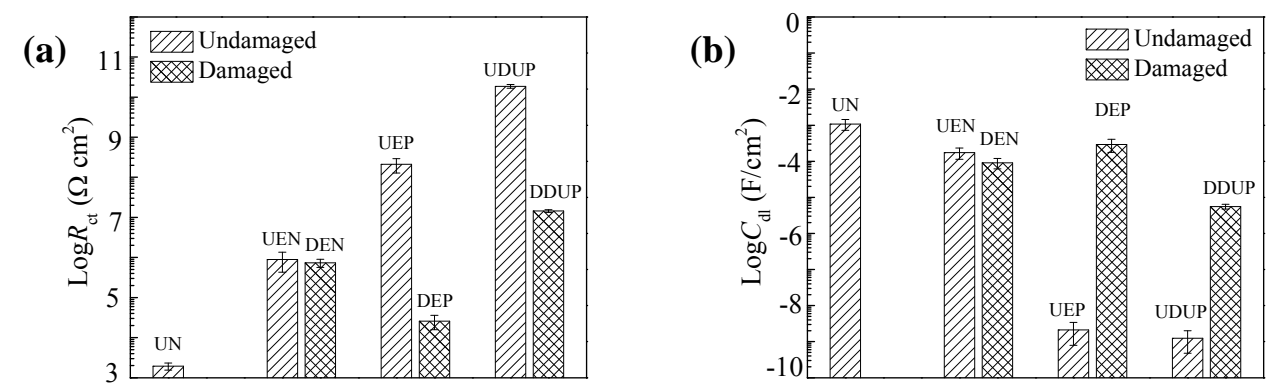

329 Fig. 9. Comparison of (a) charge transfer resistance and (b) double layer capacitance for all steel plates.

\subsubsection{Long-term corrosion in saturated $\mathrm{Ca}(\mathrm{OH})_{2}$ solution}

331 Fig. 10 shows the (average \pm standard deviation) of open-circuit potential evolution of three steel 332 plates immersed in saturated $\mathrm{Ca}(\mathrm{OH})_{2}$ solution with an increasing concentration of chloride over time. In 333 the first three days, only the open circuit potentials of three uncoated steel plates were recorded and their 334 average increased from -363 to $-198 \mathrm{mV} / \mathrm{SCE}$, which is due to the formation of a stable passive film. The 335 average potential remained stable around $-190 \mathrm{mV}$ for another 6 days till the chloride concentration was 336 increased to $0.05 \mathrm{~mol} / \mathrm{L}$. At 13 days when the chloride reached $0.10 \mathrm{~mol} / \mathrm{L}$, the potential decreased 337 dramatically to $-489 \mathrm{mV}$, indicating breakdown of the passive film and the initiation of pitting corrosion.

338 The result is consistent with studies by other researchers [52, 53]. After 13 days, the potential remained 339 stable till the end of test when the chloride concentration reached $1.00 \mathrm{~mol} / \mathrm{L}$. A drop of potential was also 340 observed for epoxy and duplex coated steel plates with impact damage and all enamel coated steel plates 341 when the chloride concentration reached $0.05 \mathrm{~mol} / \mathrm{L}$, which is also ascribed to the breakdown of passive 342 film and the initiation of pitting corrosion at the coating damaged areas for epoxy and duplex coated 343 plates, and around the open pores for enamel coated steel plates. However, the drop in open circuit potential for epoxy and duplex coated steel plates without impact damage was delayed to a chloride level of $0.50 \sim 1.00 \mathrm{~mol} / \mathrm{L}$. Therefore, both the epoxy and duplex coating increase the chloride threshold. 


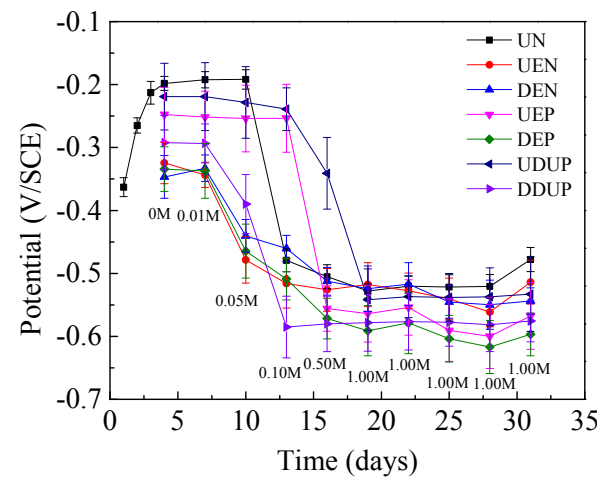

Fig. 10. Open circuit potential evolution over time in saturated $\mathrm{Ca}(\mathrm{OH})_{2}$ solution with various chloride concentrations ( $\mathrm{M}$ represents $\mathrm{mol} / \mathrm{L}$ ).

Fig. 11 shows the evolution of impedance spectrum over time for representative steel plates in saturated $\mathrm{Ca}(\mathrm{OH})_{2}$ with various chloride concentrations in the format of Bode plots. Both the experimental data (scattered symbols) and fitted data (solid lines) using the EEC models in Fig. 7 are displayed. As shown in Fig. 11a, the impedance magnitude of uncoated steel plates decreased when the chloride concentration reached $0.50 \mathrm{~mol} / \mathrm{L}$ due to breakdown of the passive film. Two time constants can be observed from the phase angle vs. frequency diagrams, particularly after the initiation of corrosion. The time constant in the high frequency is related to the properties of passive film, and the time constant in the low frequency is associated with the pitting corrosion. Therefore, the EEC model (II) in Fig. 7 was used to fit the test data, in which $R_{\mathrm{s}}$ is the electrolyte resistance, $R_{\mathrm{c}}$ is the passive film resistance, $C P E_{\mathrm{c}}$ represents the non-homogenous capacitive behavior of passive film, $C P E_{\mathrm{dl}}$ and $R_{\mathrm{ct}}$ represent the behavior of pitting corrosion. For comparison, the EEC model (II) was also employed to fit the impedance spectrum prior to the breakdown of passive film.





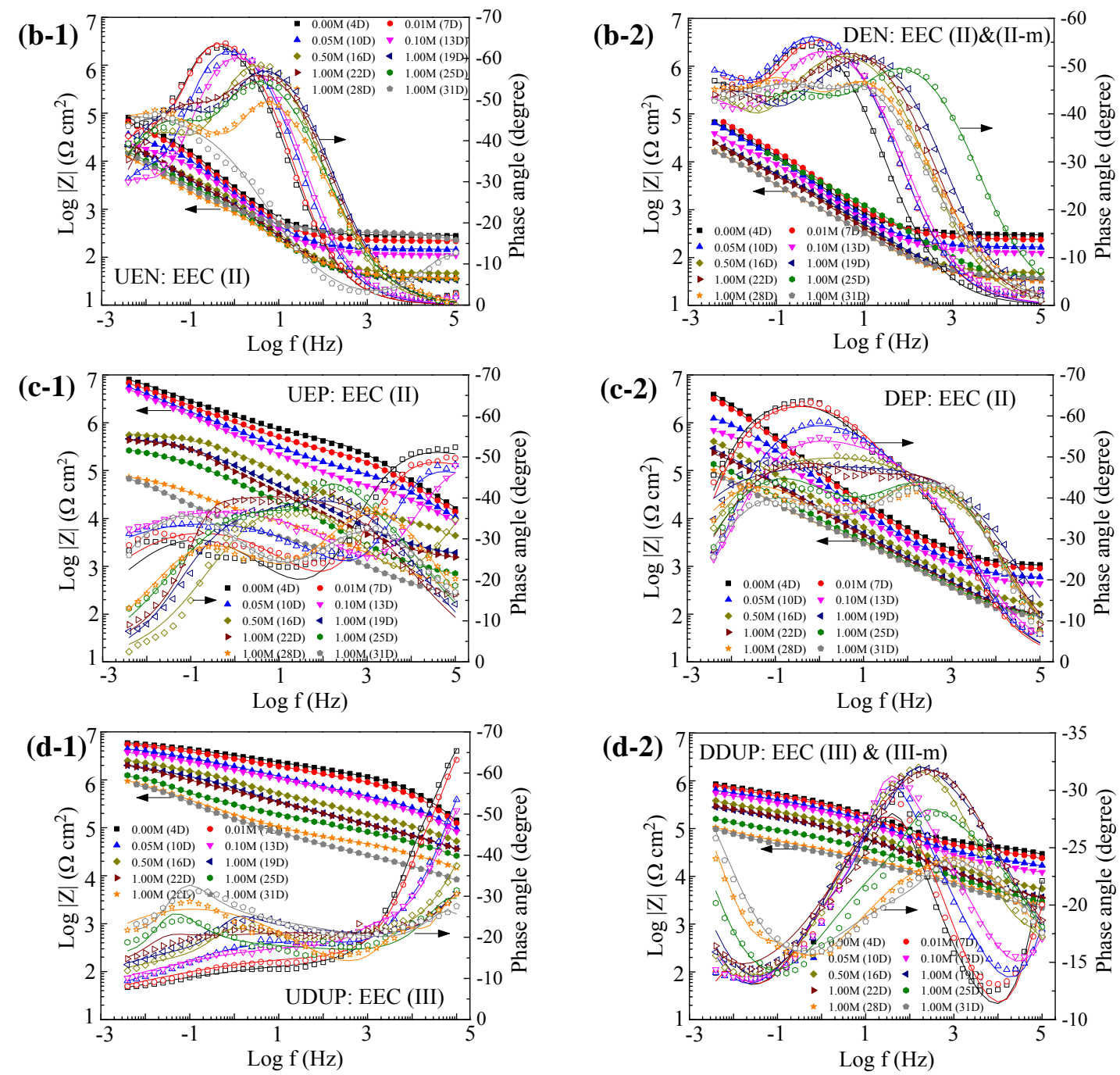

Fig. 11. Representative Bode plot of (a) uncoated (UN), (b) enamel (EN), (c) epoxy (EP), and (d) duplex (DUP) coated steel plates with (1) undamaged (U) and (2) damaged (D) in simulated concrete pore solution with various chloride concentrations. (Note: $\mathrm{D}$ in legend means days, and $\mathrm{M}$ represents $\mathrm{mol} / \mathrm{L}$ )

The impedance magnitude $|\mathrm{Z}|$ of enamel coated steel plates decreased gradually over time as shown in Fig. $11 \mathrm{~b}$, as a result of electrolyte uptake that forms conductive pathways through the coating [41]. Two time constants can be observed in the phase angle-frequency plots. The first time constant in the high frequency is related to the properties of combined enamel coating and passive film, and the second time constant in the low frequency is associated with pitting corrosion properties. Therefore, the EEC model (II) in Fig. 7 was used again. However, for the enamel coated steel plate with impact damage as shown in Fig. 11(b-2), a diffusion behavior appeared after 13 days, which is caused by the presence of corrosion 
products on the surface of corrosion active sites [54]. Thus, the modified EEC model with a Warburg diffusion impedance $W$ or EEC model (II-m) in Fig. 7 was used.

Fig. 11c shows the impedance diagrams of epoxy coated steel plates without damage (c-1) and with impact damage (c-2). The drop of impedance magnitude over one order is present for the steel plate without impact damage when the chloride reached $0.50 \mathrm{~mol} / \mathrm{L}$ as shown in Fig. 11(c-1). This is because a significant amount of chloride penetrated through the pin holes of epoxy coating to the substrate steel, resulting in the initiation of pitting corrosion. However, the impedance magnitude of the epoxy coated steel plate with impact damage reduced when the chloride reached $0.05 \mathrm{~mol} / \mathrm{L}$, which is lower than the amount of chloride for breakdown of the passive film on the epoxy steel plate without impact damage. This is because a significant portion of steel substrate was exposed to solution due to impact damage, which is vulnerable to chloride attack. For comparison, the EEC model (II) was also used to fit the EIS results of epoxy coated steel plates with and without impact damage.

As shown in Fig. 11d for duplex coated steel plates, a gradual decrease of impedance magnitude $|\mathrm{Z}|$ over time can be seen due to the electrolyte uptake of coating layer and the initiation of pitting corrosion. Steel plates with impact damage showed diffusion behavior after 13 days, which was caused by the accumulation of corrosion products on the corrosion active sites. Therefore, the EEC (III \& III-m) models were used to fit the test data for undamaged and damaged coatings, respectively, as displayed in Figs. 11(d-1) and 11(d-2).

Fig. 12a plots the pore resistance of various coatings as a function of time when the chloride concentration of solution changes. For uncoated steel plates, the coating in Fig. 12 is referred to the passive film formed on the steel surface. Due to breakdown of the passive film, the pore resistance of the uncoated plates decreased gradually from 981 to $100 \Omega \cdot \mathrm{cm}^{2}$ as the chloride concentration increased over time, which is lower than that of any coating tested. The pore resistances of coatings also decreased gradually over time due to uptake of electrolyte into the open pores, damaged areas, and pin holes. When 
the chloride concentration reached $1.00 \mathrm{~mol} / \mathrm{L}$, the pore resistance of enamel coating whether damaged or not became the smallest among all the coatings tested since more solution was penetrated into the enamel coating through its open pores as shown in Fig. 2a. The outer epoxy coating (UDUP-EP \& DDUP-EP) and the undamaged inner enamel coating (UDUP-EN) of duplex coated steel plates have the highest pore resistances $\left(\sim 28 \mathrm{k} \Omega \mathrm{cm}^{2}\right)$. However, the inner enamel (DDUP-EN) of the duplex coated steel plate with 404 impact damage has a pore resistance close to that of the enamel coating. This is likely because the electrolyte was spread among the connected pores of the inner enamel through the outer epoxy damaged areas. The pore resistances of epoxy coatings are approximately $6.1 \mathrm{k} \Omega \mathrm{cm}^{2}$ when undamaged and approximately $2.3 \mathrm{k} \Omega \mathrm{cm}^{2}$ when damaged.

(a)



(b)



Fig. 12. Change of (a) coating resistance and (b) coating capacitance over time for all steel plates in saturated $\mathrm{Ca}(\mathrm{OH})_{2}$ solution with various chloride concentrations ( $\mathrm{M}$ represents $\mathrm{mol} / \mathrm{L}$ ).

Fig. 12b displays the evolution of coating capacitance over time. The capacitance of passive film slightly fluctuated around $300 \mu \mathrm{F} / \mathrm{cm}^{2}$, which is consistent with the results from other studies [55]. The capacitance of coating was approximately $100 \mu \mathrm{F} / \mathrm{cm}^{2}$ for the enamel coated plate and approximately 0.50 $\mathrm{nF} / \mathrm{cm}^{2}$ for the duplex coated plate. However, the capacitance of coating was suddenly increased from $3.80 \mathrm{nF} / \mathrm{cm}^{2}$ to $0.76 \mu \mathrm{F} / \mathrm{cm}^{2}$ for the undamaged epoxy coated plate at a chloride concentration of 1.00 $\mathrm{mol} / \mathrm{L}$, and from $6.30 \mathrm{nF} / \mathrm{cm}^{2}$ to $0.38 \mu \mathrm{F} / \mathrm{cm}^{2}$ for the damaged epoxy coated plate at a chloride concentration of $0.05 \mathrm{~mol} / \mathrm{L}$. This is attributed to increased coating conductivity due to the penetration of chloride into the pinholes and the coating damaged area. 
By comparing Fig. 12a with Fig. 8a, the pore resistances of all coatings in the $3.5 \mathrm{wt} . \% \mathrm{NaCl}$ solution

$420(0.62 \mathrm{~mol} / \mathrm{L})$ are higher than those in saturated $\mathrm{Ca}(\mathrm{OH})_{2}$ solution with a chloride concentration of 0.50

$421 \mathrm{~mol} / \mathrm{L}$ after 16 days of immersion. Similarly, the coating capacitances of steel plates in salt solution are

422 lower than those in saturated $\mathrm{Ca}(\mathrm{OH})_{2}$ solution. This is probably because the test time (1.5 hours) in salt

423 solution is too short to allow a full penetration of chloride into the coatings through damage, open pores,

424 or pin holes.

425

426

427

428

429

430

431

432

433

434

435

436

437

438

439

440

441

442

443

Fig. 13 compares the (average \pm standard deviation) corrosion resistances of all the steel plates tested in saturated $\mathrm{Ca}(\mathrm{OH})_{2}$ solution with increasing chloride concentration in terms of charge transfer resistance and double layer capacitance. The average charge transfer resistance of three uncoated steel plates suddenly decreased from $1.03 \mathrm{M} \Omega \mathrm{cm}^{2}$ to $69 \mathrm{k} \Omega \mathrm{cm}^{2}$ as the chloride concentration changed from 0.05 $\mathrm{mol} / \mathrm{L}$ to $0.10 \mathrm{~mol} / \mathrm{L}$, indicating the breakdown of passive film and the initiation of pitting corrosion. The average charge transfer resistance of enamel coated steel plates gradually decreased over time from 210 $\mathrm{k} \Omega \mathrm{cm}^{2}$ in the beginning to $34 \mathrm{k} \Omega \mathrm{cm}^{2}$ at 31 days. The charge transfer resistances of steel plates with epoxy and duplex coatings reduced dramatically when the chloride increased from $0.10 \mathrm{~mol} / \mathrm{L}$ at 13 days to $0.50 \mathrm{~mol} / \mathrm{L}$ at 16 days, which is an indication of corrosion initiation. After 16 days, they gradually decreased over time due to the increase of chloride concentration and the enlargement of active pitting corrosion. At the completion of test in 31 days, the charge transfer resistances of all but duplex coated plates without impact damage dropped below $1 \mathrm{M} \Omega \mathrm{cm}^{2}$, indicating an active corrosion state [56, 57]. In the active state, the charge transfer resistances of epoxy and duplex coated steel plates are higher than those of the enamel coated steel plates. Steel plates without coatings have the lowest charge transfer resistance in active state.

The double layer capacitances of all steel plates generally increased with an increase of chloride concentration over time as shown in Fig. 13b, which is attributed to the enlargement of active corrosion area. The double layer capacitances of uncoated and enamel coated steel plates are around $500 \mu \mathrm{F} / \mathrm{cm}^{2}$ [55], which is higher than those of epoxy and duplex coated steel plates. This is because the area of 
445 plates. Duplex coated steel plates have the lowest double layer capacitance revealing a small active pitting 446 corrosion area.

447

448

449

450

451

452

453

454

455

456

457

458

459

460

461 (a)



(b)



Fig. 13. Evolution of (a) charge transfer resistance and (b) double layer capacitance over time for all steel plates in saturated $\mathrm{Ca}(\mathrm{OH})_{2}$ solution with various chloride concentrations ( $\mathrm{M}$ represents $\mathrm{mol} / \mathrm{L}$ ).

By comparing Fig. 13a with Fig 9a, the corrosion resistances of all but uncoated and epoxy coated steel plates with impact damage in $3.5 \mathrm{wt} . \% \mathrm{NaCl}$ solution $(0.62 \mathrm{mil} / \mathrm{L})$ are higher than their corresponding resistances in saturated $\mathrm{Ca}(\mathrm{OH})_{2}$ solution with $0.50 \mathrm{~mol} / \mathrm{L}$ chloride concentration. This is probably because the 1.5 hours test time in $3.5 \mathrm{wt} . \% \mathrm{NaCl}$ solution is too short for chloride to completely penetrate to the exposed steel through open pores, pin holes or damaged areas. The higher corrosion resistance of uncoated and epoxy coated steel plates with impact damage in saturated $\mathrm{Ca}(\mathrm{OH})_{2}$ solution is attributed to the passive film which covered most of the surface on steel plates while all the exposed steel surfaces are subjected to active corrosion in $3.5 \mathrm{wt} . \% \mathrm{NaCl}$ solution.

\section{Conclusions}

In this study, the microstructure, impact resistance, pull-off adhesion strength, and corrosion resistance of uncoated, enamel coated, epoxy coated, and duplex coated steel plates were investigated. Based on the experimental data and analysis, the following conclusions can be drawn: 
462

(1) Enamel coating is a porous layer with partly connected pores due to release of gases in the enameling process while epoxy coating is a dense layer. The duplex epoxy/enamel coating has two distinct materials; the outer epoxy fills the connected pores of the inner enamel.

(2) The duplex coated steel plate has higher impact resistance than that of individual enamel and epoxy coated plates due to its laminar structure with increasing stiffness. The duplex coating is locally dented while the enamel coating is partially chipped off in pieces due to its brittleness and the epoxy coating is significantly delaminated due to mechanical bond with its substrate steel.

(3) Enamel coating fails across the micro pores in the coating layer while both epoxy and duplex coatings show mixed failure modes at multiple locations. Epoxy coating has the highest pull-off adhesion strength due to mechanical interlocking with substrate steel while enamel and duplex coatings have slightly lower pull-off strength due to the porosity of coatings even though enamel chemically bonds with its substrate steel.

(4) In $3.5 \mathrm{wt} . \% \mathrm{NaCl}$ solution, all coatings can protect steel plates from corrosion. Duplex coated steel plates have a higher average corrosion resistance than those of individual epoxy and enamel coated steel plates, whether intact or damaged. While it has little effect on the corrosion resistance of enamel coated steel plates, coating damage significantly reduces the corrosion resistances of epoxy and duplex coated plates.

(5) In saturated $\mathrm{Ca}(\mathrm{OH})_{2}$ solution, the transition from passive to active corrosion state occurred at a chloride concentration of $0.05 \sim 0.10 \mathrm{~mol} / \mathrm{L}$ for uncoated, enamel (intact and damaged), epoxy (damaged), and duplex (damaged) coated steel plates, and at $0.50 \sim 1.00 \mathrm{~mol} / \mathrm{L}$ for epoxy (undamaged) and duplex (undamaged) coated steel plates. In active state (e.g. $0.50 \mathrm{~mol} / \mathrm{L}$ ), the corrosion resistance of duplex coating is at least $180 \%$ that of individual coatings and impact damage reduces the resistance of duplex coating by about 10 times. The corrosion resistances of all but uncoated and damaged epoxy coated steel plates are lower than those in 3.5 wt.\% $\mathrm{NaCl}$ solution where chloride may not fully penetrate through the coatings in 1.5 hours. The higher corrosion resistances of 
uncoated and epoxy coated steel plates with impact damage in saturated $\mathrm{Ca}(\mathrm{OH})_{2}$ solution is attributed to the protection of passive film.

\section{Acknowledgements}

The authors gratefully acknowledge the financial support provided by the U.S. National Science Foundation under Award No. CMMI-0900159. The enamel-coated specimens tested in this study were prepared by Pro-Perma Engineered Coatings, Rolla, Missouri.

\section{References}

[1] H. Lv, Y. Wu, Z. Fang, S. Zhou, Deterioration behavior of reinforced concrete beam under compound effects of acid-salt mist and carbon dioxide, Constr. Build. Mater. 77 (2015) 253-259.

[2] S. Mindess, J.F. Young, D. Darwin, Concrete, second edition, Prentice Hall, Upper Saddle River, New Jersey, 2002.

[3] A. Bossio, T. Monetta, F. Bellucci, G.P. Lignola, A. Prota, Modeling of concrete cracking due to corrosion process of reinforcement bars, Cement. Concrete. Res. 71 (2015) 78-92.

[4] L. Jin, R. Zhang, X. Du, Y. Li, Investigation on the cracking behavior of concrete cover induced by corner located rebar corrosion, Eng. Fail. Anal. 52 (2015) 129-143.

[5] F. Tang, Z. Lin, G. Chen, W. Yi, Three-dimensional corrosion pit measurement and statistical mechanical degradation analysis of deformed steel bars subjected to accelerated corrosion, Constr. Build. Mater. 70 (2014) 104-117.

[6] K. Bhargava, A.K. Ghosh, Y. Mori, S. Ramanujam, Corrosion-induced bond strength degradation in reinforced concrete-analytical and empirical models, Nucl. Eng. Des. 237 (2007) 1140-1157.

[7] Y. Du, M. Cullen, C. Li, Structural effects of simultaneous loading and reinforcement corrosion on performance of concrete beams, Constr. Build. Mater. 39 (2013) 148-152.

[8] W. Yi, S.K. Kunnath, X. Sun, C. Shi, F. Tang, Fatigue behavior of reinforced concrete beams with corroded steel reinforcement, ACI Struct. J. 107 (2010) 526-533.

[9] G.H. Koch, M.P.H. Brongers, N.G. Thompson, Y.P. Virmani, J.H. Payer, Corrosion costs and preventive strategies in the United States, Publication No. FHWA-RD-01-156, 2002.

[10] M.A. Blankson, S. Erdem, Comparison of the effect of organic and inorganic corrosion inhibitors on the rheology of self-compacting concrete, Constr. Build. Mater. 77 (2015) 59-65.

[11] T.A. Soylev, M.G. Richardson, Corrosion inhibitors for steel in concrete: state-of-the-art report, Constr. Build. Mater. 22 (2008) 609-622.

[12] J. Lou, D.D.L. Chung, Effect of admixtures in concrete on the corrosion resistance of steel reinforced concrete, Corros. Sci. 42 (2000) 1489-1507.

[13] F. Tittarelli, G. Moriconi, The effect of silane-based hydrophobic admixture on corrosion of reinforcing steel in concrete, Cement. Concrete. Res. 38 (2008) 1354-1357.

[14] X. Shi, Z. Yang, Y. Liu, D. Cross, Strength and corrosion properties of Portland cement mortar and concrete with mineral admixtures, Constr. Build. Mater. 25 (2011) 3245-3256.

[15] E. Oller, A. Mari, J.M. Bairan, A. Cladera, Shear design of reinforced concrete beams with FRP longitudinal and transverse reinforcement, Compos. Part B 74 (2015) 104-122. 
[16] P. Santos, G. Laranja, P.M. Franca, J.R. Correia, Ductility and moment redistribution capacity of multi-span Tsection concrete beams reinforced with GFRP bars, Constr. Build. Mater. 49 (2013) 949-961.

[17] E. Medina, J.M. Medina, A. Cobo, D.M. Bastidas, Evaluation of mechanical and structural behavior of austenitic and duplex stainless steel reinforcements, Constr. Build. Mater. 78 (2015) 1-7.

[18] S. Pour-Ali, C. Dehghanian, A. Kosari, Corrosion protection of the reinforcing steels in chloride-laden concrete environment through epoxy/polyaniline-camphorsulfonate, Corros. Sci. 90 (2015) 239-247.

[19] A. Brenna, F. Bolzoni, S. Beretta, M. Ormellese, Long-term chloride-induced corrosion monitoring of reinforced concrete coated with commercial polymer-modified mortar and polymeric coatings, Constr. Build. Mater. 48 (2013) 734-744.

[20] D.G. Manning, Corrosion performance of epoxy-coated reinforcing steel: North American experience, Constr. Build. Mater. 10 (1996) 349-365.

[21] F. Tang, G. Chen, R.K. Brow, J.S. Volz, M.L. Koenigstein, Corrosion resistance and mechanism of steel rebar coated with three types of enamel, Corros. Sci. 59 (2012) 157-168.

[22] Z. Tan, C.M. Hansson, Effect of surface condition on the initial corrosion of galvanized reinforcing steel embedded in concrete, Corros. Sci. 50 (2008) 2512-2522.

[23] M. Sanchez, M.C. Alonso, P. Cecilio, M.F. Montemor, C. Andrade, Electrochemical and analytical assessment of galvanized steel reinforcement pre-treated with $\mathrm{Ce}$ and La salts under alkaline media, Cement. Concrete. Comp. 28 (2006) 256-266.

[24] S. Rossi, N. Parziani, C. Zanella, Abrasion resistance of vitreous enamel coatings in function of frit composition and particles presence, Wear 332-333 (2015) 702-709.

[25] M.T. Kim, S.Y. Chang, O.Y. Oh, J.B. Won, H.W. Park, Failure analysis of enamel-coated carbon steel heating elements of gas-gas heater for flue gas desulfurization system, Eng. Fail. Anal. 14 (2007) 686-693.

[26] F. Tang, G. Chen, J.S. Volz, R.K. Brow, M.L. Koenigstein, Microstructure and corrosion resistance of enamel coatings applied to smooth reinforcing steel, Constr. Build. Mater. 35 (2012) 376-384.

[27] F. Tang, G. Chen, J.S. Volz, R.K. Brow, M.L. Koenigstein, Cement-modified enamel coating for enhanced corrosion resistance of steel reinforcing bars, Cement. Concrete. Comp. 35 (2013) 171-180.

[28] ASTM, Standard Test Method for impact resistance of pipeline coatings (falling weight test), American Society for Testing and Materials (ASTM), G14-04, 2010.

[29] ASTM D4541 Standard Test Method for Pull-Off Strength of Coatings Using Portable Adhesion Tester, American Society for Testing and Materials, West Conshohocken, PA. 2009.

[30] M. Criado, I. Sobrados, J. Sanz, J.M. Bastidas, Steel protection using sol-gel coatings in simulated concrete pore solution contaminated with chloride, Surf. Coat. Tech. 258 (2014) 485-494.

[31] F. Tang, X. Cheng, G. Chen, R.K. Brow, J.S. Volz, M.L. Koenigstein, Electrochemical behavior of enamelcoated carbon steel in simulated concrete pore water solution with various chloride concentrations, Electrochim. Acta. 92 (2013) 36-46.

[32] W. Chen, R. Du, C. Ye, Y. Zhu, C. Lin, Study on the corrosion behavior of reinforcing steel in simulated concrete pore solution using in situ Raman spectroscopy assisted by electrochemical techniques, Electrochim. Acta. 55 (2010) 5677-5682.

[33] X. Yang, A. Jha, R. Brydson, R.C. Cochrane, An analysis of the microstructure and interfacial chemistry of steel-enamel interface, Thin solid Films 443 (2003) 33-45.

[34] G. Ling, J. He, The influence of nano- $\mathrm{Al}_{2} \mathrm{O}_{3}$ additive on the adhesion between enamel and steel substrate, Mater. Sci. Eng. A 379 (2004) 432-436.

[35] C.H. Lin, J.G. Duh, Electrochemical impedance spectroscopy (EIS) study on corrosion performance of CrAlSiN coated steels in 3.5 wt.\% NaCl solution, Surf. Coat. Tech. 204 (2009) 784-787.

[36] C. Zhou, X. Lu, Z. Xin, J. Liu, Y. Zhang, Polybenzoxazine/ $/ \mathrm{SiO}_{2}$ nanocomposite coatings for corrosion protection of mild steel, Corros. Sci. 80 (2014) 269-275.

[37] P. Cordoba-Torres, T.J. Mesquita, R.P. Nogueira, Influence of geometry-induced current and potential distributions on the characterization of constant-phase element behavior, Electrochim. Acta. 87 (2013) 676-685. 
[38] P. Cordoba-Torres, T.J. Mesquita, O. Devos, B. Tribollet, V. Roche, R.P. Nogueira, On the intrinsic coupling between constant-phase element parameters $\alpha$ and $\mathrm{Q}$ in electrochemical impedance spectroscopy, Electrochim. Acta. 72 (2012) 172-178.

[39] H. Vakili, B. Ramezanzadeh, R. Amini, The corrosion performance and adhesion properties of the epoxy coating applied on the steel substrates treated by cerium-based conversion coatings, Corros. Sci. 94 (2015) 466475.

[40] X. Liu, Y. Shao, Y. Zhang, G. Meng, T. Zhang, F. Wang, Using high-temperature mechanochemistry treatment to modify iron oxide and improve the corrosion performance of epoxy coating-II. Effect of grinding temperature, Corros. Sci. 90 (2015) 463-471.

[41] M. F. Montemor, D.V. Snihirova, M.G. Taryba, S.V. Lamaka, I.A. Kartsonakis, A.C. Balaskas, G.C. Kordas, J. Tedim, A. Kuznetsova, M.L. Zheludkevich, M.G.S. Ferreira, Evaluation of self-healing ability in protective coatings modified with combinations of layered double hydroxides and cerium molibdate nanocontainers filled with corrosion inhibitors, Electrochimi Acta 60 (2012) 31-40.

[42] S. Amand, M. Musiani, M.E. Orazem, N. Pebere, B. Tribollet, V. Vivier, Constant-phase-element behavior caused by inhomogeneous water uptake in anti-corrosion coatings, Electrochim. Acta. 87 (2013) 693-700.

[43] Z. Kerner, T. Pajkossy, On the origin of capacitance dispersion of rough electrodes, Electrochim. Acta. 46 (2000) 207- 211.

[44] I.A. Kartsonakis, E. Athanasopoulou, D. Snihirova, B. Martins, M.A. Koklioti, M.F. Montemor, G. Kordas, C.A. Charitidis, Multifunctional epoxy coatings combining a mixture of traps and inhibitor loaded nanocontainer for corrosion protection of AA2024-T3, Corros. Sci. 85 (2014) 147-159.

[45] B. Hirschorn, M.E. Orazem, B. Tribollet, V. Vivier, I. Frateur, M. Musiani, Determination of effective capacitance and film thickness from constant-phase-element parameters, Electrochim. Acta 55 (2010) 62186227.

[46] M.S. Ghaffari, R. Naderi, M. Sayehbani, The effect of mixture of mercaptobenzimidazole and zinc phosphate on the corrosion protection of epoxy/polyamide coating, Prog. Org. Coat. 86 (2015) 117-124.

[47] X. Yuan, Z.F. Yue, X. Chen, S.F. Wen, L. Li, T. Feng, EIS study of effective capacitance and water uptake behavior of silicon-epoxy hybrid coatings on mild steel, Prog. Org. Coat. 86 (2015) 41-48.

[48] X. Liu, J. Xiong, Y. Lv, Y. Zuo, Study on corrosion electrochemical behavior of several different coating systems by EIS, Prog. Org. Coat. 64 (2009) 497-503.

[49] H.H. Hassan, E. Abdelghani, M.A. Amin, Inhibition of mild steel corrosion in hydrochloric acid solution by triazole derivatives: Part I. polarization and EIS studies, Electrochim. Acta. 52 (2007) 6359-6366.

[50] H. Zhang, X Pang, M Zhou, C Liu, L Wei, K Gao, The behavior of pre-corrosion effect on the performance of imidazoline-based inhibitor in 3 wt.\% NaCl solution saturated with $\mathrm{CO}_{2}$, Appl. Surf. Sci. 356 (2015) 63-72.

[51] A. Madhan Kumar, Zuhair M. Gasem, In situ electrochemical synthesis of polyaniline/f-MWCNT nanocomposite coatings on mild steel for corrosion protection in 3.5\% NaCl solution, Prog. Org. Coat. 78 (2015) 387-394.

[52] H. Yu, K.T.K. Chiang, L.T. Yang, Threshold chloride level and characteristics of reinforcement corrosion initiation in simulated concrete pore solutions, Constr. Build. Mater. 26 (2012) 723-729.

[53] L. Jiang, G. Huang, J. Xu, Y. Zhu, L. Mo, Influence of chloride salt type on threshold level of reinforced corrosion in simulated concrete pore solutions, Constr. Build. Mater. 20 (2012) 516-521.

[54] C. Zhu, R. Xie, J. Xue, L. Song, Studies of the impedance models and water transport behaviors of cathodically polarized coating, Electrochim. Acta 56 (2011) 5828-5835.

[55] C Ye, R Hu, S Dong, X Zhang, R Hou, R Du, C Lin, J Pan, EIS analysis on chloride-induced corrosion behavior of reinforcement steel in simulated carbonated concrete pore solutions, J. Electroanal. Chem. 688 (2013) 275-281.

[56] F. Tang, G. Chen, R.K. Brow, Chloride-induced corrosion mechanism and rate of enamel- and epoxy-coated deformed steel bars embedded in mortar, Cement. Concrete. Res. 82 (2016) 58-73. 
[57] A. Krolikowski, J. Kuziak, Impedance study on calcium nitrite as a penetrating corrosion inhibitor for steel in concrete, Electrochim. Acta. 56 (2011) 7845-7853. 